\title{
Análise fitoquímica e atividade antimicrobiana do extrato etanólico do resíduo madeireiro de Hymenaea courbaril $L$.
}

O aproveitamento dos resíduos madeireiros do gênero Hymenaea (família Fabaceae) apresenta-se como oportunidade para o desenvolvimento de produtos por apresentar em sua constituiç̃o química compostos bioativos com propriedades biológicas. Neste contexto objetivou-se verificar a composição química do extrato etanólico e frações de galhos de Hymenae courbaril e avaliar a atividade antimicrobiana frente a fungos fitopatogênicos. O material utilizado na pesquisa foi obtido de resíduos florestais de árvores de Jatobá (Hymenaea courbaril) provenientes da área de manejo localizada próximo a cidade de Santarém, Pará, Brasil. O material foi desdobrado para obtenção de serragem, a qual foi seca em estufa a $40^{\circ} \mathrm{C}$ por 96 horas e extraídos em álcool etílico no aparelho de Soxhlet e em seguida o solvente foi removido, obtendo-se a média dos rendimentos dos extratos de $16,09 \%$. Realizou-se a caracterização fitoquímica dos extratos de Hymenaea courbaril por Cromatografia em Camada Delgada (CCD) e por Cromatografia Gasosa acoplada a Espectrometria de Massa (CG-EM). Avaliou-se a ação fungitóxica dos extratos por meio da concentração inibitória mínima (CIM), e Concentração Fungicida Mínima (CFM) para os fungos Fusarium oxysporum, Aspergillus niger, Macrophomin phaseolina, Aspergillus parasiticus e Sclerotinia sclerotiorum. As classes de compostos presentes no extrato e frações de Hymenaea courbaril detectadas por CCD e CG-EM foram os ácidos graxos, terpenos, fitoesterois, taninos e flavonoides. Na CIM verificou-se atividade antimicrobiana para todos fungos testados, sendo Macrophomina phaseolina, o microrganismo mais sensivel, apresentando ação inibitória entre $1000 \mu \mathrm{g} . \mathrm{mL}-1$ até 15,625 $\mu \mathrm{g} \cdot \mathrm{mL}-1$, concluindo-se que Hymenaea courbaril pode ser uma promissora fonte alternativa no controle de fungos fitopatogênicos.

Palavras-chave: Fitoquímica; Jatobá; fitopatógenos.

\section{Phytochemical analysis and antimicrobial activity of the ethanolic extract of residue of Hymenaea courbaril L. timber}

\begin{abstract}
The use of wood residues of the genus Hymenaea (family Fabaceae) is an opportunity for the development of bioproducts due to its bioactive compounds with biological properties in their chemical constitution. In this context, the objective was to verify the chemical composition of ethanolic extracts and fractions from branches of Hymenaea courbaril and to evaluate the antimicrobial activity against phytopathogenic fungi. The material used in the research was obtained from forest residues of Jatobá trees (Hymenaea courbaril) from the management area located near the city of Santarém, Pará, Brazil. The material was unfolded to obtain sawdust, that oven-dried at $40^{\circ} \mathrm{C}$ for 96 hours and extracted in ethyl alcohol in the Soxhlet apparatus. The solvent was removed, obtaining the average yield of the extracts of $16.09 \%$. Phytochemical characterization of Hymenaea courbaril extracts was performed by Thin Layer Chromatography (TLC) and Gas Chromatography coupled to Mass Spectrometry (GC/MS). The fungitoxic action of the extracts was evaluated by means of the minimum inhibitory concentration (MIC), and Minimum Fungicidal Concentration (MFCs) for the fungi Fusarium oxysporum, Aspergillus niger, Macrophomina phaseolina, Aspergillus parasiticus and Sclerotinia sclerotiorum. The classe of compounds present in the Hymenaea courbaril extract and fractions detected by TLC and GC/MS were fatty acids, terpenes, phytosterols, tannins and flavonoids. In the MIC, antimicrobial activity was verified for all tested fungi, and Macrophomina phaseolina was the most sensitive microorganism, with an inhibitory action between $1000 \mu \mathrm{g}$. $\mathrm{mL}-1$ to $15.625 \mu \mathrm{g}$. $\mathrm{mL}-1$, concluding that Hymenaea courbaril can be a promising alternative source to control phytopathogenic fungi.
\end{abstract}

Keywords: Phytochemistry; Jatobá; Fhytopathogens.

Sara Freitas de Sousa (BD

Universidade Federal do Oeste do Pará, Brasil http://lattes.cnpq.br/0444579834038751 http://orcid.org/0000-0002-1305-8514 sara freitas stm@hotmail.com

Aline Aparecida Munchen Kasper (iD) Universidade Federal do Oeste do Pará, Brasil http://lattes.cnpq.br/8775156657725568 http://orcid.org/0000-0003-2613-5125 aliny@msn.com.br

José Jeosafa Vieira de Sousa Júnior (iD Universidade Federal do Oeste do Pará, Brasil http://lattes.cnpq.br/2162716940839053 http://orcid.org/0000-0001-8790-0711 josejeosafajrstm@hotmail.com

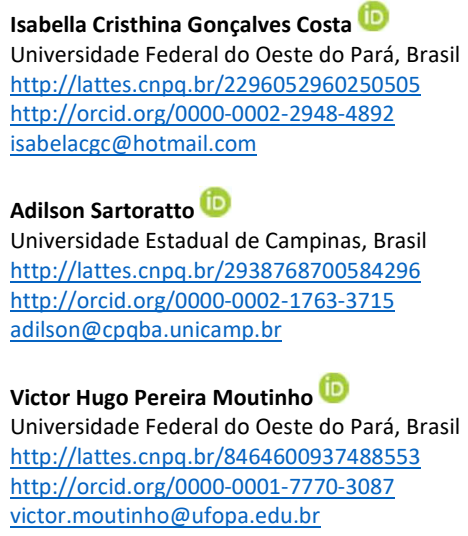

victor.moutinho@ufopa.edu.br

Sílvia Katrine Rabelo da Silva (it)

Universidade Federal do Oeste do Pará, Brasi http://lattes.cnpq.br/6999618172919722 http://orcid.org/0000-0002-9408-131X katrinerabelos@gmail.com

\section{Lauro Euclides Soares Barata (iD)}

Universidade Federal do Oeste do Pará, Brasi http://lattes.cnpq.br/1609747051706094 http://orcid.org/0000-0003-0909-769X lauroesbarata@gmail.com

\section{Referencing this:}

SOUSA, S. F.; KASPER, A. A. M.; SOUSA JUNIOR, J. J. V.; COSTA, I. C. G.; SARTORATTO, A.; MOUTINHO, V. H. P.; SILVA, S. K. R.; BARATA, L. E. S.. Análise fitoquímica e atividade antimicrobiana do extrato etanólico do resíduo madeireiro de Hymenaea courbaril L.. Revista Ibero Americana de Ciências Ambientais, v.11, n.4, p.72-80, 2020. DOI: http://doi.org/10.6008/CBPC2179-6858.2020.004.0006 


\section{INTRODUÇÃO}

O Brasil é conhecido por ser um país florestal, sendo que as áreas estimadas de florestas naturais e plantadas em 2018 foi de aproximadamente 498 milhões de hectares, correspondendo à 58,47\% do seu território (57,31\% florestas naturais e 1,16\% florestas plantadas), sendo a segunda maior área de florestas do mundo, atrás apenas da Rússia (IBGE, 2018). A Amazônia possui 325.469 .969 ha de cobertura florestal, onde se estima que o volume de madeira total seja aproximadamente 84.749 milhões de $\mathrm{m}^{3}$, correspondendo a $87,16 \%$ dos biomas brasileiros (SFB, 2013).

Estratégias de gestão de resíduos e seu aproveitamento na indústria madeireira torna-se de fundamental importância, especialmente em espécies do gênero Hymenaea. Ao analisar as guias florestais emitidas pelo Sistema de Comercialização e Transporte de Produtos Florestais - SISFLORA entre 2009 e 2015, verifica-se a geração de aproximadamente $750.000 \mathrm{~m}^{3}$ de resíduos de Jatobá na forma de galho acima de 20cm de diâmetro, se usadas as estimativas de Silva-Ribeiro et al. (2013) e Monteiro et al. (2010).

O gênero Hymenaea é descrito por ter potencial antifúngico, antibacteriano, inseticida, larvicida ou antitermítico, sendo essas atividades associadas à sua composição química, constituindo assim, uma importante fonte de compostos químicos oriundos do seu metabolismo secundário, tornando-se uma alternativa e oportunidade para diversos setores da indústria farmacêutica e biotecnológica (LORENZI et al., 2002).

Fernandes et al. (2005) afirmam que o jatobá possui componentes químicos, como taninos e flavonoides, cujos compostos estão provavelmente associados à ação antifúngica. De modo geral, a maioria das espécies inclusas neste gênero são conhecidas por terem madeiras de boa qualidade, resinas, frutos, cascas com alto teor de taninos e com um amplo espectro de utilização (LORENZI et al., 2002; BEZERRA et al., 2013).

As classes de compostos mais presentes em Hymenaea são os flavonoides, compostos fenólicos e terpenoides, e possivelmente estes são os responsáveis pelas características antimicrobianas atribuídas ao gênero (PETTIT et al., 2003; MARANHÃO et al., 2009). Bezerra et al. (2013) ao realizarem uma abordagem fitoquímica da casca de Hymenaea courbaril verificou a presença de polifenóis como flavonoides e taninos, assim como antociânicos, triterpenóides e saponinas. Alguns metabólitos isolados das cascas, do tronco, dos galhos e das folhas de $\mathrm{H}$. courbaril já foram descritos, tais como os flavonóides eucrifina, epicatequina, luteolina, crisoerio, os diterpenos abietano, pimarano, labdano, ácido labdanólico, além de uma lignana (palstatina) (PETTIT et al., 2003; GONÇALVES et al., 2005; MARANHÃO, 2009; COSTA, 2012; FERNANDES et al., 2005), entretanto, informações referentes à madeira de cerne de Hymenaea courbaril se fazem escassas.

As espécies deste gênero possuem grande valor econômico devido a madeira, resinas e frutas, além de também possuírem significativa importância social devido ao uso de sua casca na medicina popular. Assim, a investigação farmacológica tanto de extratos bruto, como de frações e substâncias isoladas seguem indicações terapêuticas empíricas, muitas vezes atribuídas por estudos etnobotânicos (BEZERRA et al., 2013; CIPRIANO et al., 2014). 
Estudos farmacológicos têm revelado as atividades anestésica, analgésica e anti-inflamatória do extrato do Jatobá, sendo relatado também outras atividades como ação antibacteriana, antifúngica, moluscocidas, miorrelaxante, antiespamódicas, antioxidante também já foram descritas (LORENZI et al., 2002; BEZERRA et al., 2013; CIPRIANO et al., 2014).

Os extratos vegetais e seus metabólitos secundários podem também serem fortes aliados à indústria, seja esta farmacêutica, têxtil e/ou agrícola. Em se tratando da agricultura, sabe-se que é grande a procura por métodos alternativos que possam ser utilizados para o controle de pragas e doenças, principalmente devido estes serem capazes de ocasionarem a decomposição de substratos celulósicos, tombamento de mudas, mortalidade de mudas/plantas, podridão de sementes, morte de plântulas, cancros, podridões de raízes, estagnação de crescimento, murchas, manchas, queimas, podridão de estacas, do colo da planta, tombamento, mofo, dentre outros (VIDA et al., 2004; MICHEREFF et al., 2005; ABDEL-MONAIM et al., 2011). Para isso, objetivou-se realizar o estudo fitoquímico e avaliar a atividade antimicrobiana frente à fungos fitopatogênicos do extrato dos resíduos madeireiros de Hymenaea courbaril e de suas frações.

\section{MATERIAIS E MÉTODOS}

\section{Caracterização da área de coleta, procedência, espécies e amostragem utilizada}

O material utilizado na pesquisa é proveniente de uma área de manejo da Empresa Rondobel Florestal, próximo à comunidade de Cachoeira do Aruã, localizado no município de Santarém-PA. O local de coleta apresenta temperaturas médias anuais entre 26 e 28 ํㅡ, umidade alta, valores médios anuais entre 80 a $85 \%$, com os totais anuais médios de pluviosidade variando entre 2.000 e $2.800 \mathrm{~mm}$, sendo a tipologia vegetal predominante de Floresta Ombrófila Densa (ICBMBIO, 2014) (Figura 1).

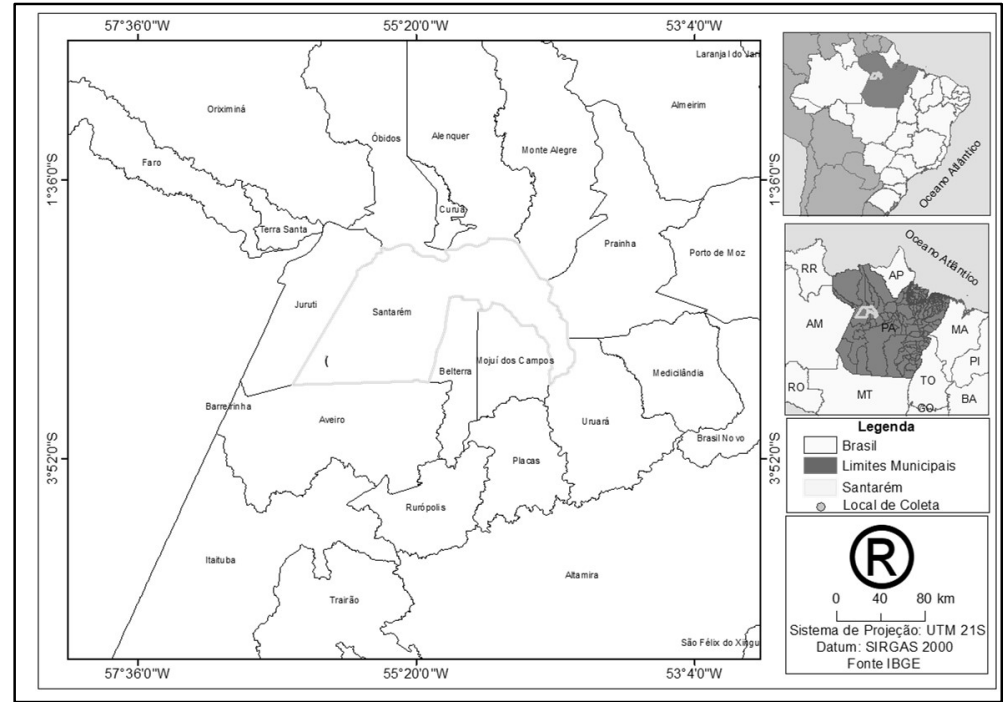

Figura 1: Mapa de localização da região de coleta das árvores de Hymenaea courbaril.

A seleção de indivíduos ocorreu aleatoriamente, onde coletou-se material dos resíduos florestais de galhos de três indivíduos de Hymenaea courbaril após a segunda bifurcação, onde parte de cada amostra obtida foi encaminhada para xiloteca da Universidade Federal do Oeste do Pará para a devida confirmação da identificação por especialistas. O material foi posteriormente desdobrado em plaina devidamente 
higienizada afim de evitar contaminação, visando a coleta de serragem. Posteriormente, as amostras foram secas em estufa $\left(40^{\circ} \mathrm{C}\right.$ por $\left.96 \mathrm{~h}\right)$, homogeneizados em granulometria e armazenados em sacos de papel para a realização das extrações de cada indivíduo.

\section{Obtenção do extrato}

O extrato alcóolico foi preparado a partir de 50g de serragem seca e $1000 \mathrm{~mL}$ de etanol 92,8 INPM, sendo destilado e tratado com hidróxido de sódio. A extração foi realizada em aparelho de Soxhlet por 8h, em triplicata. $\mathrm{O}$ extrato foi concentrado sob pressão reduzida a $50^{\circ} \mathrm{C}$ em evaporador rotativo, com sistema de refrigeração acoplado (Fisatom, modelo 801), sendo as amostras pesadas, armazenadas em frascos âmbar hermeticamente fechados e mantidas sob refrigeração $\left(10^{\circ} \mathrm{C}\right)$ (TAUBE JUNIOR et al., 2014). Os rendimentos das extrações foram calculados em função da massa de produto obtido em razão da massa vegetal extraída multiplicada por 100 .

\section{Partição líquido-líquido do extrato etanólico de jatobá}

Para a partição líquido-líquido $3 \mathrm{~g}$ de extrato etanólico foram solubilizados em $150 \mathrm{~mL}$ de solução etanol-água 70:30, a qual foi transferida para um funil de separação, para realização da partição líquidolíquido, utilizando os solventes segundo a sua polaridade: hexano, diclorometano e acetato de etila ( 3 X 30 $\mathrm{mL}$ cada). As soluções obtidas foram reunidas, secas com sulfato de sódio $\left(\mathrm{Na}_{2} \mathrm{SO}_{4}\right)$, filtradas e concentradas em evaporador rotativo à pressão reduzida. Após esses processos, as frações foram analisadas por Cromatografia Gasosa acoplada a Espectrometria de Massa (CG-EM).

\section{Cromatografia em Camada Delgada (CCD)}

A caracterização fitoquímica do extrato de Jatobá foi inicialmente realizada por Cromatografia em Camada Delgada (CCD). Para isto, foram utilizadas placas de alumínio $(10 \times 10 \mathrm{~cm})$ e sílica Merk 60 mesh com indicador fluorescente $254 \mathrm{~nm}$ e espessura da camada de $0,20 \mathrm{~mm}$. Foram solubilizados $10 \mathrm{mg}$ do extrato em $1 \mathrm{~mL}$ de etanol, sendo aplicado $10 \mu \mathrm{L}$ na placa cromatográfica. As fases móveis foram preparadas de acordo com a polaridade do extrato, ocorrendo a separação de substâncias nas placas. Para a revelação das placas utilizou-se a irradiação com lâmpada ultravioleta (UV) nos comprimentos de onda de $254 \mathrm{~nm}$ e 366 nm. A revelação química foi realizada com o revelador adequado para cada classe de metabólito.

\section{Cromatografia Gasosa acoplada a Espectrometria de Massa (CG-EM)}

A caracterização do extrato bruto e das frações foi realizada em Cromatógrafo a Gás acoplado a Espectrômetro de Massas (Agilent, modelo: HP-6890) acoplado a detector seletivo de massas. Para análise dos compostos voláteis do extrato do resíduo dos galhos de jatobá, foi preparado uma coluna capilar HP$5 \mathrm{MS}(30 \mathrm{~m} \times 0,25 \mathrm{~mm} \times 0,25 \mathrm{~mm})$, com temperatura do injetor de $250^{\circ} \mathrm{C}$, temperatura do detector de $300^{\circ} \mathrm{C}$, temperatura da coluna de $80 \circ \mathrm{C}$, gás de arraste $\mathrm{He} 1,0 \mathrm{~mL} \cdot \mathrm{min}^{-1}$. Os espectros de massa gerados foram comparados com os disponibilizados pela biblioteca NIST05 e bibliografia Adams (2007). 


\section{Derivatização do extrato e frações}

Foi realizado a derivatização do extrato etanólico, hexânico, diclorometano e acetato de etila na proporção de $10 \mathrm{mg}$ de extrato e $2 \mathrm{~mL}$ de solução $\mathrm{CH}_{2} \mathrm{Cl}_{2}: \mathrm{MeOH}$ (90:10) com o reagente trimetilsilildiazometano (TMSD), para otimizar a volatilidade dos compostos presentes na amostra e permitir a sua identificação (BOAVENTURA JUNIOR, 2015).

\section{Concentração inibitória mínima (CIM)}

Para o ensaio antifúngico foram utilizadas suspensões de Aspergillus niger, Aspergillus parasiticus, Fusarium oxysporum, Sclerotinia sclerotiorum e Macrophomina phaseolina, ajustadas na escala de 0,5 MacFarland equivalente a $1,5 \times 10^{4}$ esporos. $\mathrm{mL}^{-1}$. A CIM foi determinada pelo método de microdiluição em placas de Elisa de 96 poços. O teste ocorreu em meio líquido Batata-Dextrose (BD) nas concentrações do extrato entre 1000 - 15,625 $\mu \mathrm{g} \cdot \mathrm{mL}^{-1}$. Na última linha da placa de microdiluição foi realizado o controle de esterilidade do meio, o controle positivo com o antifúngico comercial Azimut ${ }^{\circledR}$ e a avaliação da viabilidade dos patógenos. $O$ ensaio foi realizado durante $96 \mathrm{~h}$, sendo feito a aplicação de $10 \mu \mathrm{L}$ de solução de resazurina a 0,01\% como indicador colorimétrico de viabilidade celular e, posteriormente, determinada a concentração fungicida pela subcultura de uma alíquota de $10 \mu \mathrm{L}$ do conteúdo dos poços correspondente a CIM, em meio sólido Ágar Batata-Dextrose (BDA).

\section{RESULTADOS}

Foi verificado o rendimento médio de 16,09\% para o extrato etanólico de Hymenaea courbaril, e a partir da partição líquido-liquido foram obtidos os seguintes rendimentos: fração hexânica (1,93\%), fração diclorometânica $(76,84 \%)$, fração acetato de etila $(15,08 \%)$ e fração aquosa $(16,50 \%)$. Por meio da CCD verificou-se que o extrato etanólico do resíduo madeireiro de Hymenaea courbaril possui em sua composição classes de compostos como terpenos, flavonoides e taninos. As demais classes avaliadas (alcaloides, cumarinas e derivados antracênicos) apresentaram resultados negativos após a revelação química.

Não foi possível identificar compostos voláteis no extrato por CG-EM. Entretanto, após utilização da técnica de derivatização, pode-se identificar os terpenos, éster metílicos do ácido 5,5,8abetadecahidrotetrametil-2-metileno-1-naftalenopentanoico (Figura 2A), e do éster metílico do ácido 2hidroxibetadecahidro-2,5,5,8a-pentametil naftalenopentanoico (Figura 2B). A fração hexânica do Jatobá apresenta, como esperado, substâncias de características apolares, embora tenha sido observado um padrão no perfil de massas moleculares, indicando as possíveis classes de metabólitos pertencentes aos ácidos graxos, diterpenos e fitoesteroides, conforme a Figura 3.

Adicionalmente, não foi possível identificar nenhum composto nas frações diclorometânica e acetato de etila, pois pela a CG-EM identifica-se apenas compostos voláteis. Foi observado ação antifúngica do extrato etanólico de Hymenaea courbaril, sendo o fitopatógeno Macrophomina phaseolina o microrganismo mais sensível na concentração de 15,625 $\mu \mathrm{g} \cdot \mathrm{mL}^{-1}$ (Tabela 1). Verificou-se também atividade para os demais 
fitopatógenos testados, a qual a ação inibitória do extrato etanólico foi até a concentração de $125 \mu \mathrm{g} \cdot \mathrm{mL}^{-}$ ${ }^{1}$ para os fungos Aspergillus niger, Aspergillus parasiticus, Fusarium oxysporum e Sclerotinia sclerotiorum.

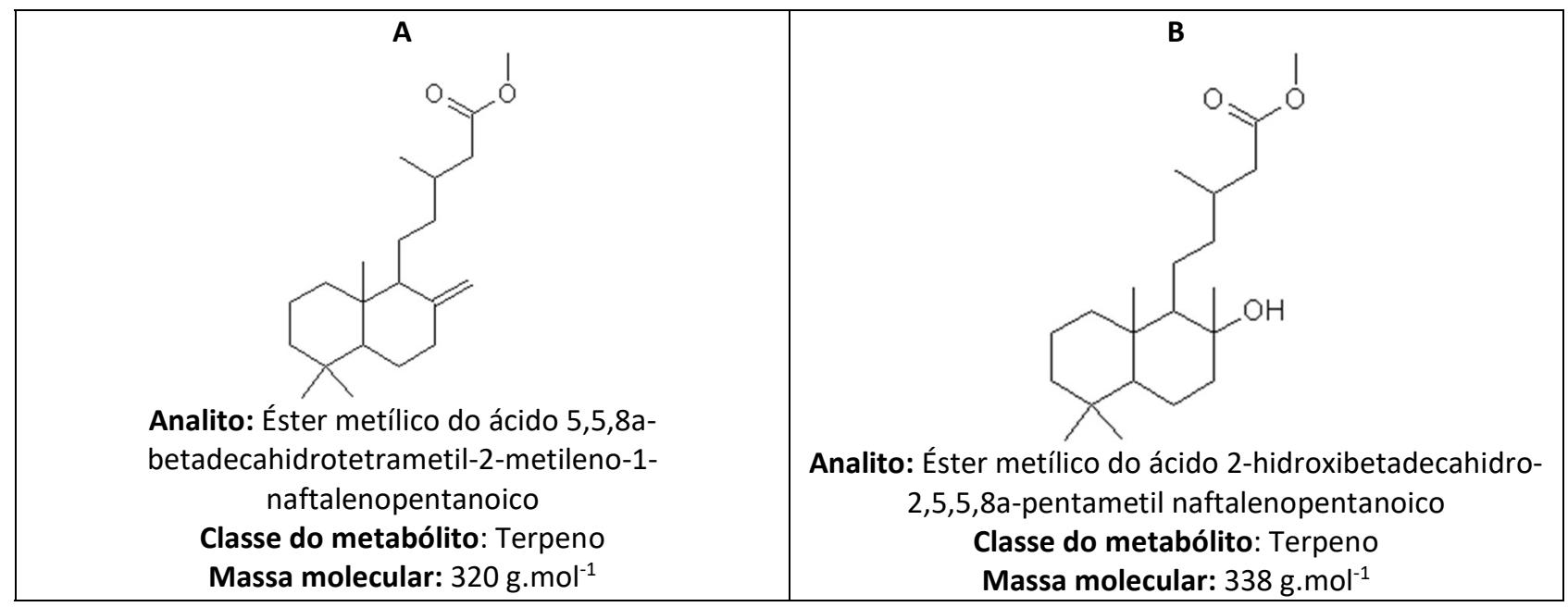

Figura 2: Substâncias encontradas no extrato etanólico bruto de Hymenaea sp.

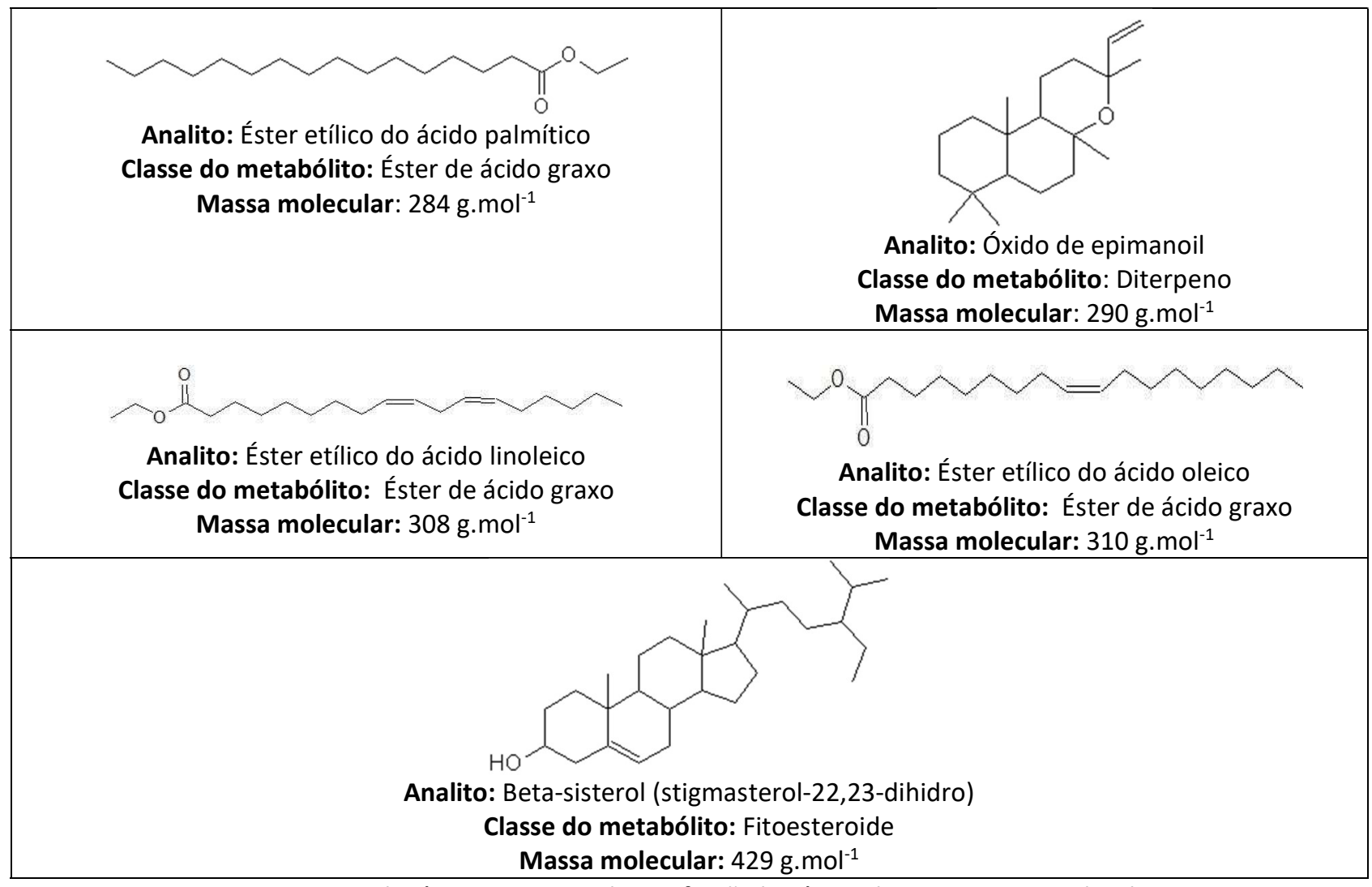

Figura 3: Substâncias encontradas na fração hexânica de Hymenaea courbaril.

Ao avaliar a CFM se verificou que para M. phaseolina a concentração fungicida foi de $250 \mu \mathrm{g} \cdot \mathrm{mL}^{-1}$, e para Sclerotinia sclerotiorum $1.000 \mu \mathrm{g} \cdot \mathrm{mL}^{-1}$, confirmando assim a ação antifúngica do extrato etanólico. Para os microrganismos Aspergillus niger e Fusarium oxysporum o extrato etanólico apresentou ação fungistática até à concentração $15,625 \mu \mathrm{g} \cdot \mathrm{mL}^{-1}$.

As frações hexânica, $\mathrm{CH}_{2} \mathrm{Cl}_{2}$ e aquosa apresentaram ação fungicida na concentração de $250 \mu \mathrm{g} \cdot \mathrm{mL}^{-1}$ contra Aspergillus parasiticus. As frações AcOEt e aquosa apresentaram ação fungicida na concentração de $250 \mu \mathrm{g} \cdot \mathrm{mL}^{-1}$ contra Fusarium oxysporum, seguido das frações hexânica e $\mathrm{CH}_{2} \mathrm{Cl}_{2}$ na concentração de 500 
$\mu \mathrm{g} \cdot \mathrm{mL}^{-1}$. Para o fungo Aspergillus niger as frações hexânica e $\mathrm{CH}_{2} \mathrm{Cl}_{2}$, apresentaram ação fungicida na concentração $500 \mu \mathrm{g} \cdot \mathrm{mL}^{-1}$, seguido da fração aquosa na concentração de $1000 \mu \mathrm{g} \cdot \mathrm{mL}^{-1}$.

Tabela 1: Determinação da concentração inibitória mínima (CIM) do extrato e frações do resíduo de Hymenaea courbaril frente a fungos fitopatogênicos.

\begin{tabular}{|c|c|c|c|c|c|c|c|c|c|c|}
\hline \multirow[t]{3}{*}{ Fitopatógeno/Extrato } & \multicolumn{2}{|l|}{$\begin{array}{l}\text { Ext. } \\
\text { EtOH }\end{array}$} & \multicolumn{2}{|c|}{ Fração hexânica } & \multicolumn{2}{|c|}{$\begin{array}{l}\text { Fr. } \\
\mathrm{CH}_{2} \mathrm{Cl}_{2}\end{array}$} & \multicolumn{2}{|c|}{$\begin{array}{l}\text { Fr. } \\
\text { AcOEt }\end{array}$} & \multicolumn{2}{|c|}{$\begin{array}{l}\text { Fração } \\
\text { Aquosa }\end{array}$} \\
\hline & CIM & CFM & CIM & CFM & CIM & CFM & CIM & CFM & CIM & CFM \\
\hline & \multicolumn{10}{|l|}{$\mu \mathrm{g} \cdot \mathrm{mL}^{-1}$} \\
\hline Aspergillus niger & 125 & $*$ & 250 & 500 & 125 & 500 & 125 & * & 1000 & 1000 \\
\hline Aspergillus parasiticus & 125 & $*$ & 250 & 250 & 250 & 250 & 500 & 500 & 250 & 250 \\
\hline Fusarium oxysporum & 125 & $*$ & 250 & 500 & 250 & 500 & 250 & 250 & 250 & 250 \\
\hline Sclerotinia sclerotiorum & 125 & 1000 & 125 & 125 & 62,5 & 62,5 & 125 & 250 & 125 & 250 \\
\hline Macrophomina phaseolina & 15,625 & 250 & 125 & 250 & 125 & 125 & 125 & 250 & 125 & 250 \\
\hline
\end{tabular}

*fungistático; CIM- Concentração inibitória mínima; CFM - Concentração fungicida mínima; $\mathrm{Fr}_{\text {. }} \mathrm{CH}_{2} \mathrm{Cl}_{2}-$ fração diclorometânica; Fr. EtOH- fração etanólica; Fr. AcOEt - fração acetato de etila.

\section{DISCUSSÃO}

Nas condições submetidas nesse estudo o rendimento médio do extrato etanólico de Hymenaea courbaril foi alto, sendo este de $16,09 \%$. Quando analisado os rendimentos obtidos do fracionamento do extrato etanólico por meio da partição líquido-líquido, o rendimento da fração diclorometânica foi superior $(76,84 \%)$ ao rendimento das demais frações, sugerindo que os compostos presentes no extrato etanólico bruto possuem maior afinidade a este solvente. Sobre isto, Veggi (2009) enfatiza que o rendimento da extração dos constituintes da planta é influenciado pelas condições de execução do processo de extração.

Ao analisar o rendimento obtido na fração acetato de etila (15,08\%), nota-se que este foi superior ao encontrado por Maranhão (2009) o qual constatou rendimento relativo de 12,7\% para o extrato acetato de etila do cerne de Hymenaea stigonocarpa Mart. ex Hayne. Verificou-se que conforme diminuía a concentração do extrato, sua ação permanecia, sendo este efeito observado até a $250 \mu \mathrm{g} \cdot \mathrm{mL}^{-1}$ para o fungo Macrophomina phaseolina. O mesmo ocorreu para a fração acetato de etila em que este extrato foi eficiente no controle de Fusarium oxysporum, Sclerotinia sclerotiorum e Macrophomina phaseolina, sendo fungicida até à concentração de $250 \mu \mathrm{g} \cdot \mathrm{mL}^{-1}$. Brandão (2004) afirma que a resposta de um microrganismo é uma função direta do log da concentração da substância teste.

A ação fungistática do extrato etanólico de Hymenaea courbaril frente a $F$. oxysporum é superior ao encontrado por Maranhão (2009) com extrato de Hymenaea stigonocarpa, sendo efetivo na concentração de $4.500 \mu \mathrm{g} \cdot \mathrm{mL}^{-1}$. O extrato etanólico e as frações obtidas do resíduo da madeira de Jatobá foram ativos contra os microrganismos testados. A ação antifúngica de espécies do gênero Hymenaea courbaril também foi descrita frente aos fungos fitopatogênicos Colletotrichum gloeosporioides, Fusarium moniliforme, Fusarium oxysporum, Fusarium solani, Verticillium lecanii, Rhizopus stolonifer, Aspergillus flavus, Phanerochaete chrysosporium (SOLINO et al., 2012; MARANHÃO, 2009; MERCÊS, 2015).

A presença de terpenos, flavonoides e taninos no extrato etanólico da madeira de Hymenaea courbaril também é descrito no estudo de Fernandes et al. (2005), que enfatizam que o jatobá possui metabólitos das classes de taninos e flavonoides, cujos compostos estão provavelmente associados à atividade antifúngica do gênero. Imai et al. (2008) e Maranhão (2009) ao realizarem abordagens fitoquímica 
do cerne da madeira de Hymenaea stignorcapa Mart. ex Hayne, também verificaram a presença significativa de flavonoides, esteroides e terpenos, corroborando com os resultados encontrados.

Por meio da análise dos constituintes de CG-MS, verificou-se a presença de substâncias das classes de terpenos e fitoesteróides. Valentim (2006) ao analisar os constituintes apolares do alburno de Hymenaea stigonocarpa constatou a presença de flavonoides, esteroides e triterpenóides, além de identificar compostos como hexadecanoato de metila $\left(\mathrm{AHS}_{2}\right)$, ácido hexadecanóico, ácido 9-ocadecenoico, ácido octadecanoico, todos isolados do extrato cicloexânico. Adicionalmente foi constatado a ação antimicrobiana de extratos cicloexano, acetato de etila e etanol através do método de microdiluição. Com isso, verifica-se que estudos comprovam que os extratos obtidos da madeira, casca, galhos, sementes e folhas das plantas pertencentes a este gênero, são promissores na busca por novos agentes antimicrobianos, o que estimula pesquisas futuras a fim de que tanto o extrato como os metabólitos, isolados e identificados a partir deste, possam ser aplicados na indústria e na agricultura, como por exemplo, no controle de pragas e doenças (VENTUROSO et al., 2011; SANTOS et al., 2019).

\section{CONCLUSÕES}

Os produtos obtidos do resíduo madeireiro do jatobá contêm os metabólitos secundários de interesse investigados, bem como apresentam ação antifúngica in vitro contra os fungos fitopatogênicos testados. Esses achados são importantes, visto a problemática de resistência microbiana à fungicidas sintéticos, os quais estão associados à diversos problemas, tanto para o meio ambiente como para a saúde humana.

Diante do exposto, verifica-se que o extrato etanólico foi mais ativo contra o fungo Macrophomina phaseolina, e com relação a partição líquido-líquido, a fração diclorometânica foi mais efetiva para Sclerotinia sclerotiorum, tendo ação fungicida para este fungo. Com isso, verifica-se que tanto o extrato como as frações obtidas da partição líquido-líquido do resíduo da madeira de Hymenaea courbaril podem ser uma fonte alternativa de moléculas antifúngicas promissoras no controle de fitopatógenos como Fusarium oxysporum, Aspergillus niger, Macrophomina phaseolina, Sclerotinia sclerotiorum e Aspergillus parasiticus, podendo esta atividade estar relacionada a diferentes classes de metabólitos. Os resultados demonstrados nesta pesquisa podem servir de base para estudos de bioprospecção biomonitoradas de possíveis produtos naturais utilizados no controle de fungos fitopatogênicos.

\section{REFERÊNCIAS}

ABDEL-MONAIM, M. F.; ABO-ELYOUSR, K. A. M.; MORSY, K. M.. Effectiveness of plant extracts on suppression of damping-off and wilt diseases of lupine (Lupinus termis Forsik). Crop Protection, v.30, n.1, p.185-191, 2011. DOI: http://doi.org/10.1016/j.cropro.2010.09.016

BEZERRA, G. P.; GÓIS, R.W.; BRITO, T. S.; LIMA, F.J.; BANDEIRA, M. A.; ROMERO, N. R.; MAGALHÃES, P. J.; SANTIAGO, G. M.. Phytochemical study guided by the myorelaxant activity of the crude extract, fractions and constituent from stem bark of Hymenaea courbaril L. Journal of Ethno Pharmacology, Bethesda, v.149, n.1, p.62-69, 2013. DOI: $\underline{\text { http://doi.org/10.1016/j.jep.2013.05.052 }}$

BOAVENTURA JUNIOR, S.. Síntese de derivados da artemisinina e estudos da atividade is vitro contra Schistosoma mansoni. Dissertação (Mestrado em Biociências e Tecnologia de produtos bioativos) Universidade Estadual de Campinas, Campinas, 2015.

BRANDÃO, G. C.. Isolamento biomonitorado de substâncias antimicrobianas de Polygonum spectablil Mart e 
determinação da CIM para uma chalcona antimicrobiana. Dissertação (Mestrado em Ciências Farmacêuticas) Universidade Federal de Minas Gerais, Belo Horizonte, 2004.

CIPRIANO, J.; MARTINS, L.; DEUS, M. S. M.; PERON, A. P.. O gênero Hymenaea e suas espécies mais importantes do ponto de vista econômico e medicinal para o Brasil. Caderno de Pesquisa, Santa Cruz do Sul, v.26, n.2, p.41-51, 2014.

COSTA, M. P. D.. Atividade biológica da seiva e de compostos extraídos da seiva de Hymenaea courbaril sobre leveduras e fungos filamentosos. Dissertação (Mestrado em Medicina Tropical e Saúde Pública) - Universidade Federal de Goiás, Goiânia, 2012

FERNANDES, T. T.; SANTOS, A. T. F.; PIMENTA, F. C. Atividade antimicrobiana das plantas Phathymenia reticulada, Hymenaea courbaril e Guazuma ulmifolia. Patologia Tropical, Goiânia, v.39, n.2, p.113-122, 2005.

GONÇALVES, A. L.; ALVES FILHO, A.; MENEZES, H.. Estudo comparativo da atividade antimicrobiana de extratos de algumas árvores nativas. Arquivos do Instituto Biológico, São Paulo, v.72, n.3, p.353-358, 2005.

IMAI, T.; INOUE, S.; OHDAIRA, N.; MATSUSHITA, Y.; SUZUKI, R.; SAKURAI, J. M. H. J.; OZAKI, S. K.. Informações ambientais vegetação vetores escala 250 mil Brasil. 2008.

IBGE. Instituto Brasileiro de Geografia e Estatística. Mapa de vegetação brasileira. Rio de Janeiro: IBGE, 2018.

LORENZI, H.. Árvores brasileiras: manual de identificação e cultivo de plantas arbóreas nativas do Brasil. 5 ed. Nova Odessa: Plantarum, 2008.

MARANHÃO, C. A.. Estudo químico, antimicrobiano, larvicida e antitermítico do cerne da madeira de lei Hymenaea stigonocarpa Mart. ex Hayne. Tese (Doutorado em química) - Universidade Federal de Pernambuco, Recife, 2009.

MERCÊS, P. F. F.. Variação da composição química e da atividade antifitopatogênica dos óleos essenciais das folhas e frutos de Hymenaea courbaril L. var. courbaril (Fabaceae) coletadas em área de extrema importância biológica para a conservação. Dissertação (Mestrado em Ciências Biológicas) - Universidade Federal de Pernambuco, Recife, 2015.

MICHEREFF, S. J.; ANDRADE, D. E. G. T.; MENEZES, M.. Ecologia e manejo de patógenos radiculares em solos tropicais. Recife: UFRPE, 2005.

ICMBIO. Instituto Chico Mendes de Conservação da Biodiversidade. Plano de manejo reserva extrativista tapajós-arapiuns. ICMBIO, 2014.

MONTEIRO, K. F. G.; KERN, D. C.; RUIVO, M. D. L. P.; RODRIGUES, T. E.; COMETTI, J. L. S.. Use of waste wood as an alternative to improve environmental conditions in the system of reforestation in Tailândia/PA. Acta Amazônica,
Manaus, v.40, n.3, p.409-413, 2010. DOI:

http://doi.org/10.1590/S0044-59672010000300001

PETTIT, G.; GEORGE, R.; PETTIT, Y. M.; CLARE, Y. M.; STEVENSON, D. L.; DOUBEK, J. C.; KNIGHT, C.; PETTIT, R. K.; CHAPUIS, J. C.; SCHMIDT, J. M.. Isolation and structure of Palstatin from the Amazon tree Hymenaea palustris. Journal of Natural Products, v.66, n.2, p.259-262, 2003. DOI: http://doi.org/10.1021/np020231e

SANTOS, H. L. L. R.; SOUZA, N.; MACEDO, N. R.; RAMOS, J. P S.; DIAS JÚNIOR, A. F.; NASCIMENTO, A.. Phytochemical Analysis of Extracts from the Atlantic Forest Wood Species. Floresta e Ambiente, Rio de Janeiro, v.26, n.1, p.18, 2019.

SFB. Serviço Florestal Brasileiro. Floresta do Brasil em resumo. Brasília: SFB, 2013.

SILVA-RIBEIRO, R. B.; GAMA, J. R. V.; SOUZA, A. L.; LEITE, H. B.; SOARES, C. P. B.; DA SILVA, G. F.. Métodos para estimar o volume de fustes e galhos na floresta nacional do Tapajós. Revista Árvore, Viçosa, v.40, n.1, p.81-88, 2016. DOI: http://doi.org/10.1590/0100-67622016000100009

SOLINO, A. J. S.; ARAÚJO NETO, S. E.; SILVA, A. N.; RIBEIRO, A. M. S.. Severidade da antracnose e qualidade dos frutos de maracujá-amarelo tratados com produtos naturais em pós-colheita. Revista Brasileira de Fruticultura, Jaboticabal São Paulo, v.34, n.1, p.57-66, 2012. DOI: http://doi.org/10.1590/S0100-29452012000100010

TAUBE JUNIOR, P. S.; CASTRO, K. C. F.; BARATA, L. E. S. Experimentos de Química. Santarém: UFOPA, 2014.

VALENTIM, A. P. T.. Atividade antimicrobiana, estudo fitoquímico e identificação de constituintes apolares do alburno de Hymenaea stigonocarpa Mart. ex. Hayne (jatobá). Dissertação (Mestrado em Biotecnologia de Produtos Bioativos) -Universidade Federal de Pernambuco, Recife, 2006

VEGGI, P. C.. Obtenção de extratos vegetais por diferentes métodos de extração: estudo experimental e simulação dos processos. Dissertação (Mestrado em Engenharia de Alimentos) - Universidade Estadual de Campinas, Campinas, 2009.

VENTUROSO, L. R.; BACCHI, L. M. A.; GAVASSONI, W. L.; CONUS, L. A.; PONTIM, B. C. A.. Atividade antifúngica de extratos vegetais sobre o desenvolvimento de fitopatógenos. Summa Phytopathologica, v.37, n.1, p.18-23, 2011. DOI: http://doi.org/10.1590/S010054052011000100003

VIDA, J. B.; ZAMBOLIM, L.; TESSMANN, D. J.; BRANDÃO FILHO, T.; VERZIGNASSI, J. R.; CAIXETA, M. P.. Manejo de doenças de plantas em cultivo protegido. Fitopatologia Brasileira, Brasília, v.29, n.4, p.355-372, 2004. DOI: http://doi.org/10.1590/S0100-41582004000400001

A CBPC - Companhia Brasileira de Produção Científica (CNPJ: 11.221.422/0001-03) detém os direitos materiais desta publicação. Os direitos referem-se à publicação do trabalho em qualquer parte do mundo, incluindo os direitos às renovações, expansões e disseminações da contribuiç̃o, bem como outros direitos subsidiários. Todos os trabalhos publicados eletronicamente poderão preservam os direitos autorais, mas não têm permissão para a publicação da contribuição em outro meio, impresso ou digital, em português ou em tradução. 